\title{
Online Media Surveillance: Coverage of Meningitis Outbreaks in Ghana
}

\author{
By Marquita S. Smith* \\ Gilbert K. M. Tietaah
}

\begin{abstract}
This study explores the nature of reportage on meningitis outbreaks in Ghana by two online media outlets, graphiconline and myjoyonline. Specifically, the study was designed to explore the news frames, level of prominence, sources of information and surveillance function performed by the media during an infectious disease outbreak. Framing was the main theoretical framework that guided the study. The content analysis method was employed to assess a total of 60 published news articles during a four-month period, December 1, 2015 to March 31, 2016. The findings revealed that "action" and "consequence" were the major frames the media used to report on meningitis outbreaks. Stories about the meningitis health crisis in Ghana were not displayed prominently online. Although the web publications generally promote multimedia content, few videos, podcasts, photos or online polls were utilized. In terms of sourcing, the online meningitis stories featured mostly government representatives and health officials and did little to engage residents and communities affected. The online media also failed to fulfill their surveillance function of reporting on trends and alerting the public of severity of the outbreak in Ghana. Given the findings, it is suggested that journalists interested in health reporting such as the meningitis outbreak receive extensive media training in order to report trends and perform their surveillance role.
\end{abstract}

Keywords: Framing, Ghana, Meningitis, Online Media, Surveillance

\section{Introduction}

Meningitis outbreaks continue to plague African nations, particularly the 26 countries located in the region called the "the Meningitis Belt", which stretches from Senegal in the west to Ethiopia in the east. While only the Upper West and Northern regions of Ghana are located in the Meningitis Belt, residents in communities across the nation experience the public health threat annually, leading invariably to hundreds of fatalities every year. Agier et al. (2013) observe that the recurrence of unpredictable epidemics in Africa makes meningitis a particularly daunting public health concern. In 2016, a strain of the disease caused large-scale outbreaks in Ghana and neighboring Togo (World Health Organization 2017). According to the World Health Organization, Ghana, with a total population of 27 million, reported 2,406 suspected cases and 222 meningitis deaths in 2016. In Togo, with total population of 7.3 million, reported 1834 suspected cases, including 118 deaths (World Health Organization 2017).

A condition which affects the spinal cord and the brain, the highly infectious disease has received unremitting clinical attention and intervention by health scientists and policy actors. This has included massive vaccination efforts in Ghana and other countries within the meningitis belt. Notwithstanding this, Ghana

\footnotetext{
${ }^{*}$ Fulbright Scholar, Department of Communication Studies, University of Ghana, Ghana \& Associate Professor, John Brown University, USA.

${ }^{\dagger}$ Lecturer, Department of Communication Studies, University of Ghana, Ghana.
} 
continues to experience high fatality rates, with deaths occurring between $36 \%$ and 50 percent of all infections (Awingura and Awoonor-Williams 2015). Researchers suggest that "poor quality of data, poor motivation, delayed reporting of health events and inadequate feedback for public health action" contribute to the large number of meningitis deaths (Awingura and Awoonor-Williams 2015: 2). As a tropical disease, meningitis outbreaks typically occur between November and March. For that reason, this study explored the extent of online media coverage of the outbreak in Ghana from December 1, 2015 to March 31, 2016.

The role of the media in drawing public attention, in influencing audience attitudes and in prompting recommended behavior has long been established (Kiousis 2011, McCombs 2005). This means that whether and how the media report an issue would affect how people receive, perceive and respond to that issue. With particular reference to health, it means also that the media are instrumental in promoting education, in alerting on risk, in exercising surveillance, and generally, in contributing to prevention and cure of public health conditions. We argue that part of the reason for the lack of observable progress in preventing or mitigating the perennial morbidity and mortality rates of meningitis infections in Ghana may lie in a failure of the media to do more than merely report the outbreak. To verify this claim, two online news websites, graphiconline and myjoyonline, were examined. Graphic Online is the web version for the Daily Graphic, a state owned daily newspaper. Myjoyonline is the web extension for Joy $F M$, a private radio station in Ghana. The two online media were selected principally for their differences in typology. Graphiconline is the online extension of the Daily Graphic newspaper; myjoyonline is the online presence of the Joy FM radio station. Additionally, graphiconline is state-owned; myjoyonline is privatelyowned. They are also under the proprietorship, respectively, of the dominant newspaper and radio station in Ghana, according to consecutive GeoPoll audience statistics.

Given that meningitis is a seasonal, predictable, outbreak in Ghana, it is understood that the disease will remain an existential news story. For this reason, this article sought to answer the following questions:

- RQ1: How much journalistic attention/treatment was given to the meningitis outbreak on the online platforms of the Daily Graphic and Joy FM?

- RQ2: What were the dominant frames appearing in online media reportage of meningitis outbreak?

- RQ3: How was sourcing used to frame credibility in news reports of the outbreak of meningitis?

This study is vital to developing an understanding about the role the media play in public health messaging in Ghana. As Schiavo (2014: 51) has pointed out, "If adequately used and selected in response to audience's needs and preferences, radio, television, printed media, and the Internet are powerful connectors between communicators and their audience". Additionally, this article will serve as useful reference on the effectiveness of online media in covering meningitis and other disease outbreaks. 


\section{Mass Communication and Health}

Both traditional and online media have a responsibility to exercise surveillance over and inform the public on disease outbreaks, and to warn and educate them on health risks and general wellbeing. In this endeavor, accuracy and fairness are espoused values, and the viewers, listeners and readers of media output approach their products on account of trust. The public have the legitimate expectation that health reports in particular will be free from sensationalism, especially health reports. Furthermore, during a health crisis, citizens want information on how to prevent infection and what treatments should be pursued. Goldsmith and Albrecht (2011: 335) stated that supportive communication is "a necessary condition for the quality of life and for healthful living". Still, scholars suggest that mass media are a powerful channel for distributing health messages which influence behavior changes. In addition, media and communication play a key role in not only providing solutions to health problems but also further resources on where to gain support. According to Tchuenche et al. (2011), health practitioners rely on the media to deliver preventive health messages to the public. The media also have the capacity to prevent people from engaging in health risk behavior.

In addition to alerting the public about preventive measures, Chen and Murphy (2011) suggested that media coverage of health issues influences the public's obedience to safety measures. Collinson et al. (2015) examined the effects of media reports on containing the spread of diseases. The researchers concluded that mass media campaigns are able to curtail the spread of diseases, and that the media play a vital role in promoting measures against these diseases.

Conversely, other scholars have maintained that media coverage may not be as useful in terms of educating the public on controlling disease outbreaks, citing that journalists have their own conventions for reporting information from health experts or sources and often do not provide the necessary depth of reporting. Additionally, the journalists tend to focus on exceptional cases or on the number of fatalities resulting from disease outbreaks (Hilton and Hunt 2010, Steinbrook 2000, Kline 2006, Vasterman and Ruigrok 2013, Carducci et al. 2011). Kline (2006) agreed that media coverage can be problematic because coverage is too often limited to fatalities and fallacious framing of the issues. Similarly, Steinbrook (2000) noted that journalists face quite a challenge in reporting health issues as they have to explain complicated information and medical terms in a way the public can easily understand. If journalists fail to properly understand and translate medical information, then the public will receive inaccurate accounts (Kline 2006, Steinbrook 2000). While media organizations value accuracy, errors or misinformation in health-related news stories are common (Kline 2006.) One way journalists can attempt to help with their learning curve is to interview expert sources and dedicate more time and space to the complex health-related topics (Erickson et al. 1989, Medeiros and Massarani 2010).

In this regard, online news websites have become particularly instrumental platforms for generating, updating and sharing health and disease outbreak information. This is not surprising considering as the literature suggests (Cortesi 
and Gasser 2015, Perrin 2015) that in the new, digital and internet-enabled, technologies age, audiences are increasingly taking to online media as alternatives to traditional (print and broadcast) news sources. In Ghana, while the potential of online media as sources of health news consumption is admittedly constrained by such factors as low literacy and limited accessibility, in this study, we were particularly interested in their capacity and role as intermedia sources. As both news aggregators and news breakers, online media are also relied on by, the traditional media to produce and disseminate health news and information through what Messner and Distaso (2008) refer to as the news source cycle. In that regard, online platforms become, also, a window of insight into what the general public might be receiving and consuming as health news and information; either via other (traditional) media or interpersonally through the two-step (or multi-step) flow process.

\section{Literature Review}

The literature is equivocal on the role of media coverage on public response to infectious disease outbreaks. Some results reflect the surveillance role of the media in alerting and arming audiences with information and knowledge for preventing the incidence, or mitigating the consequence, of the outbreak of infectious diseases. For instance, a study by Collinson et al. (2015) on the effects of media reports on the spread of diseases showed that mass media campaigns are able to stem the spread of diseases and aid the public in adopting recommended remedies. Other studies suggest that media coverage can be counterintuitive to the goal and prospect of disease prevention when news stories spread speculation, myth and misinformation (Eysenbach 2008, $\mathrm{Hu}$ and Sundar 2010). In the digital media age in which online portals have become de facto breaking news hubs, scholarly questions arise about the extent to which online news sources in Ghana constitute the echo chamber for promoting public awareness and education, or else for perpetrating falsehood and fear. This concern is particularly important in the developing country context of Ghana where there is a large deficit in the supply of health personnel per population. According to the 2014, National Development Planning Commission (NDPC) report, Ghana has a doctor-to-population ratio of $1: 10,170$. At the same time, there is a particularly high dependence on media as source of public information (Tietaah 2015).

The framing theory (Goffman 1974, Entman 1993) offers a compass by which we examine the incidence, and explain the implications, of online media coverage of the perennial outbreaks of the meningitis disease in Ghana. Gitlin (1980: 6) explicates frames as "the principles of selection, emphasis and presentation composed of little tacit theories about what exists, what happens, and what matters". As an attributes-based model, framing theory suggests that how the media represent, and as such give meaning to stories impacting the awareness, attitudes and actions of people towards the subject of those reports. The approach is appropriate because people tend to assess mediated health 
information using affect - rather than cognitive - heuristics (Peters 2011). Research has long established that individuals use media coverage as forms of cognitive shortcut for making sense of such complex issues (Shih et al. 2008, Scheufele 1999). With specific reference to infectious disease outbreaks Shih et al. (2008: 142) argue that "his might especially be the case ... because people usually do not have direct experience in coping with them". Given that online publications are particularly prone to dubitable credulity (Kim and Johnson 2009, Cassidy 2007, Flanagin and Metzger 2000) whether and how they frame disease outbreak stories are literally questions of life and death. Framing theory suggests that the media have the ability to influence audience attitudes and, in turn, actions on an issue based on the way news stories are portrayed.

We sought, therefore, to adduce empirical evidence on whether coverage of the meningitis epidemic by the two major online news portals was potentially helping or hindering preventive and precautionary healthcare efforts. To this end, we follow Shih et al.'s (2008) taxonomy of frames for assessing media coverage of public health issues. Specifically, we sought to determine the dominant dynamics surrounding online media coverage of meningitis outbreaks in Ghana according to the following six categories: reassurance, action, consequence, new evidence, conflict and uncertainty. Shih et al. (2008: 145) argued that each of these specific factors is especially suited for judging media coverage of public health epidemics. Using empirical evidence from the literature, they demonstrated that media generally pay greatest attention to issues of crisis and conflict, uncertainty and reassurance; new or emergent evidence, the impact or consequence of disease, and recommendations on how to act in response to the outbreak. The results of their study showed that action and consequence were the dominant frames in the coverage of three public health epidemics (mad cow disease, West Nile virus, and avian flu) by the New York Times.

In their study of media coverage of the $2009 \mathrm{H} 1 \mathrm{~N} 1$ pandemic in the Netherlands, Vasterman and Ruigrok (2013) concluded that framing was the product of journalistic narratives consciously grafted to expert sources in order to gain purchase on credibility. Pribble et al. (2010) studied how public health officials communicated the emergence of the West Nile Virus in the media and the main factors that influenced coverage. Similar to the Vasterman and Ruigrok (2013) study, Pribble et al. (2010) were interested in observing the presence and nature of source attributions in the stories. They found that fewer than three in 10 stories had public health experts as their sources. Online and other media articles were used as alternative sources of information to the public. Stories that included public health officials as their sources were found to be thematically framed as they gave more insight into the characteristics of the disease. On the contrary, Berry et al. (2007) examined the quantity and framing of health stories on the outbreak of SARS (Sudden Acute Respiratory Syndrome). They found the majority of news stories attributed expert sources. To that extent, we were interested in how the two media outlets, graphiconline and myjoyonline, might increase credibility, which is generally lacking in online platforms through their use of source attribution frames. 


\section{Methodology}

The study employed the content analysis method of enquiry to identify the trends and patterns of coverage of the latest meningitis outbreak in Ghana by the graphiconline and myjoyonline news portals. It also sought to assess the extent and prominence the two news portals attached to the meningitis outbreak. Data collection spanned four months from December 1, 2015 through March 31, 2016. The timeframe coincides with the period of seasonal manifestations of meningitis outbreaks in the country. In Ghana, morbidity and mortality records normally peak between January and February. The study assessed all stories on meningitis within the specified timeframe to find out if, and how, the two media were contributing to alert and educate the public on the imminence, presence and consequences of the disease outbreak.

In all, 60 stories were retrieved through a simple keyword search for mentions of "meningitis". Coding was primarily undertaken by one researcher and ensued iteratively according to thematic coding principles. Each of these stories was reviewed and coded according to such factors as subject matter of story, frames used, and sources attributed, if any. The units of analyses consisted of every straight news item, feature article, opinion or editorial or readers' letters, rejoinders or retractions. These items were coded according to the six news frame categories identified by Shih et al. (2008); namely: consequence, uncertainty, action, reassurance, conflict and new evidence. Consequence referred to the attributes of impact of the disease; such as loss of human lives, numbers and identities of affected or infected people, social and political issues generated by the outbreak or economic implications of meningitis. Uncertainty was coded for where sources expressed uncertainties about the disease; such as the cause, spread and control of the disease. Action referred to any steps or action taken by authorities to control and curb the spread of the disease. Conflict was used to identify stories in which opinions differed among sources with regards to the most effective measures to curb the spread of the disease, or how serious the impact of the disease was on the public. New evidence described reports of findings arising from research; such as new strains/types of the disease, newly discovered vaccines, or modes of transmission.

The sources attributed were categorized according to the factors suggested by Medeiros and Massarani (2010). Specifically, sources referred to persons or institutions that provided information to create the news story. This is important because the identity and professional authority of the sources helps repose credibility to the story. Following the categorization developed by Vasterman and Ruigrok (2013) tone of coverage was coded as either alarming, neutral or reassuring. Items were also coded in terms of whether or not there were enhancements in the forms of accompanying pictures, audio or videos illustrations. Finally, size of story was analysed in terms of word length as short (less than 400 words), medium (more than 400 words but less than 1,000 words), or long (more than 1,000 words). The coded items were processed and analysed using the Statistical Package for Social Sciences (SPSS) software and the data were presented in the form of frequency distribution tables, bar charts and pie charts. 
The key findings were also synthesized for the purpose of answering the two research questions indicated above.

\section{Data Analysis and Interpretation}

In this section, the findings of the research are presented. The study examined the frames with which online media - graphiconline and myjoyonline - covered the meningitis outbreak in Ghana from December 1, 2015 to March 31, 2016. Additionally, researchers evaluated the sources of information in the news stories and reviewed the dominant tone and level of prominence attached to the outbreak of meningitis.

\section{Prominence of Health Stories}

When discussing dominant frames, one question this study sought to answer was the level of prominence attached to the coverage of meningitis outbreak by two online media in Ghana. We understand that there is a news hierarchy which correlates with the value of the news. The more prominent the news stories the more likely they will be to influence residents and public officials to take notice of the health concern. The figures below (frequencies, tables and charts) present findings on the level of prominence attached to the coverage of meningitis outbreak in Ghana by graphiconline and myjoyonline. The variables under consideration were: story distribution by month, type of story, length of story and type of story enhancement. Together, they helped to answer RQ1: What were the dominant frames appearing in online media reportage of meningitis outbreak?

Table 1. Story Distribution by Month

\begin{tabular}{|l|c|c|}
\hline Month & Frequency & Percent \\
\hline December & 0 & 0 \\
\hline January & 29 & 48.3 \\
\hline February & 22 & 36.7 \\
\hline March & 9 & 15.0 \\
\hline Total & $\mathbf{6 0}$ & $\mathbf{1 0 0 . 0}$ \\
\hline
\end{tabular}

A total of 60 stories were coded over the four-month period. January 2016 was the month that recorded the highest amount of coverage with 29 stories. The findings show that no story was recorded in December (2015) prior to the outbreak of the meningitis (Table 1). 
Figure 1. Type of News Story

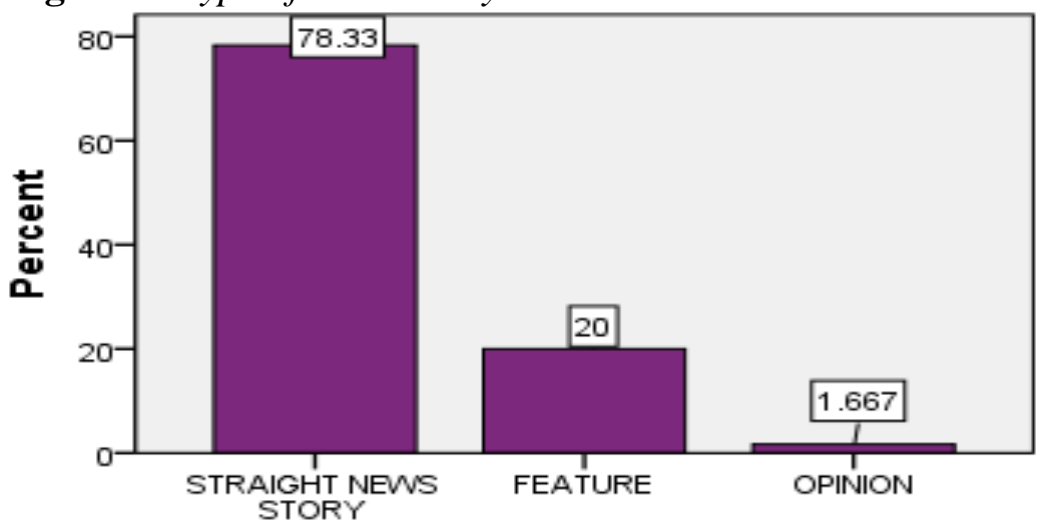

Figure 1 highlights the distribution of items according to the type of stories found on the two websites. The majority of stories on meningitis were straight or hard news items, which addressed the core questions - who, what, when, where, why, and how. Close to four in five $(78.33 \%)$ of stories analyzed were straight news items. Features were ranked second with $20 \%$, and opinion stories recorded $1.6 \%$ of sampled stories.

Figure 2. Length of Story

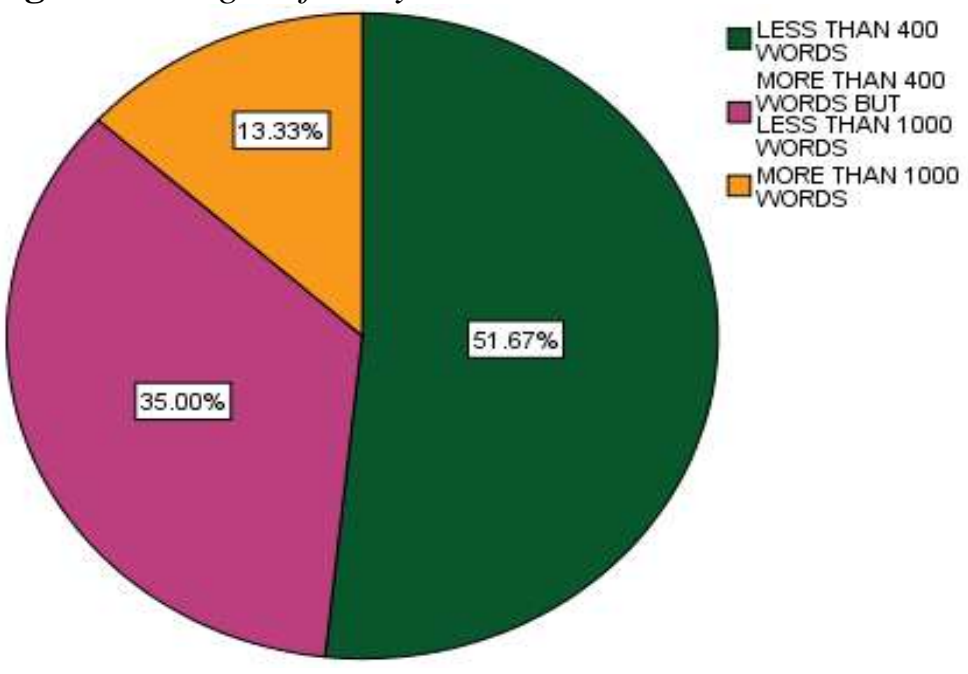

Figure 2 indicates the frequency distribution of stories according to their length. More than half (51.67\%) of sampled stories had less than 400 words which was considered as short. The next category focused on reports with more than 400 words but less than 1,000 words (35\%) while stories with more than 1,000 words recorded the least number of stories at $13.3 \%$.

Looking beyond story length, it was discovered that the majority $(86.6 \%)$ of stories on meningitis were enhanced with photo visuals. Making up 3.3\%, were news stories published with text only, or stories which included either video or audio. Only $1.7 \%$ of stories included both picture and video, which are the particular news enhancement attribute of online media. 
Evaluating story prevalence provides key insights on the display and framing of the news articles. The figures below (frequencies, tables and charts) present findings on the frames. The variables under consideration were: subject matter, tone, treatment/remedy framing, key issues reported and the types of frames. Half of the stories on meningitis published on graphiconline and myjoyonline centered on awareness creation. Of the other remaining 30 stories, 22 were coded as providing caution/alert on the risks of meningitis infection. On the other hand, three stories had research and development pertaining to meningitis as the subject matter while five stories which did not fall into either awareness creation, caution/risks or research and development were coded as other.

It was observed that 39 stories representing $65 \%$ had neutral tones while 12 stories $(20 \%)$ had alarming tones describing the meningitis outbreak in terms of fatalities and risks. Also, nine stories, representing $15 \%$ of coded articles, had reassuring tones. It can be summarized that majority of stories had neutral tones in their reportage, which means that news items contained both perspectives of reassurance and risk (alarm).

Table 2. Type of Frame

\begin{tabular}{|l|c|c|c|}
\hline \multirow{2}{*}{ Frame } & \multicolumn{2}{|c|}{ Responses } & \multirow{2}{*}{ Percent of Cases } \\
\cline { 2 - 3 } & $\mathbf{N}$ & Percent & \\
\hline Consequence & 34 & 50.0 & 56.7 \\
\hline Uncertainty & 2 & 2.9 & 3.3 \\
\hline Action & 22 & 32.4 & 36.7 \\
\hline Reassurance & 4 & 5.9 & 6.7 \\
\hline Conflict & 2 & 2.9 & 3.3 \\
\hline None & 4 & 5.9 & 6.7 \\
\hline Total & $\mathbf{6 8}$ & $\mathbf{1 0 0 . 0}$ & $\mathbf{1 1 3 . 3}$ \\
\hline
\end{tabular}

Half of all coded stories recorded consequence as frames describing the meningitis outbreak in terms of impact and risks on the public. Over $30 \%$ of the news stories had action frames, which refer to action steps taken to curb the spread of the disease. Also, almost 3\% of coded stories had frames of uncertainty. Frames of reassurance and conflict recorded over $6 \%$ and $3 \%$ respectively (Table 2).

Table 3. Key Issues Reported

\begin{tabular}{|l|c|c|c|}
\hline \multirow{2}{*}{ Issues } & \multicolumn{2}{|c|}{ Responses } & Percent of \\
\cline { 2 - 3 } & $\mathbf{N}$ & Percent & Cases \\
\hline Number of deaths recorded & 35 & 38.5 & 59.3 \\
\hline Number of new cases recorded & 9 & 9.9 & 15.3 \\
\hline $\begin{array}{l}\text { Comparison with past meningitis } \\
\text { outbreaks }\end{array}$ & 3 & 3.3 & 5.1 \\
\hline Symptoms of the disease & 5 & 5.5 & 8.5 \\
\hline Infection control & 31 & 34.1 & 52.5 \\
\hline Modes of transmission & 8 & 8.8 & 13.6 \\
\hline Total & $\mathbf{9 1}$ & $\mathbf{1 0 0 . 0}$ & $\mathbf{1 5 4 . 2}$ \\
\hline
\end{tabular}


Table 3 provides information on the key issues the media report on during disease outbreaks and subsequently how these issues are framed. The findings show that majority of stories $(38.5 \%)$ reported on the number of deaths recorded as the disease spread across Ghana. The second most reported angle (34\%) focused on the ability (or inability) of health officials and government leaders to control the spread of the disease. The number of new meningitis cases represented almost $10 \%$ of stories while reports on modes of transmission were $8.8 \%$; symptoms of the disease and comparison with past meningitis outbreaks recorded $5.5 \%$ and $3 \%$, respectively. Moreover, the findings show that a greater number of stories $(60 \%)$ did not suggest any remedies for meningitis or any suggestions for reducing the spread of the disease. However, $20 \%$ of stories suggested government intervention as a solution for containing the outbreak. The last two frames, adherence to precautionary measures and vaccination as remedy for the disease, both recorded $10 \%$.

Table 4. Sources of Information

\begin{tabular}{|l|c|c|c|}
\hline \multirow{2}{*}{ Sources } & \multicolumn{2}{|c|}{ Responses } & \multirow{2}{*}{ Percent of Cases } \\
\cline { 2 - 3 } & $\mathbf{N}$ & Percent & \\
\hline Government representative & 31 & 44.9 & 51.7 \\
\hline Health official & 16 & 23.2 & 26.7 \\
\hline International authority & 3 & 4.3 & 5.0 \\
\hline Scientist & 1 & 1.4 & 1.7 \\
\hline Ordinary citizen & 1 & 1.4 & 1.7 \\
\hline $\begin{array}{l}\text { Non-governmental } \\
\text { organization }\end{array}$ & 1 & 1.4 & 1.7 \\
\hline Politician & 6 & 8.7 & 10.0 \\
\hline Journalist initiated & 9 & 13.0 & 15.0 \\
\hline Other & 1 & 1.4 & 1.7 \\
\hline Total & $\mathbf{6 9}$ & $\mathbf{1 0 0 . 0}$ & $\mathbf{1 1 5 . 0}$ \\
\hline
\end{tabular}

Table 4 shows the frequency distribution of meningitis stories by the sources of information. The majority of the stories (44.9\%) featured a government representative, including spokespersons from the Ministry of Health, as their primary sources. Meanwhile, $23 \%$ of the stories highlighted interviews with health officials (public health officials, doctors, Ghana Health Service employees). Despite media ethicist's recommendations, journalists published $13 \%$ of stories with anonymous sources. The next most popular source of information included politicians with $9 \%$. International bodies such as the World Health Organization and other international bodies corded 3\% of stories.

\section{Discussion}

Understanding the role media, particularly online publications, play in covering meningitis outbreaks in Ghana, was the primary goal of this research project. Specifically, the study explored how graphiconline and myjoyonline 
reported the last meningitis outbreak from December 1, 2015 to March 31, 2016. A total of 60 articles were retrieved online and coded to determine the level of prominence, the dominant frames and sources of information for news coverage. As mentioned earlier, scholarly opinion is divided on the role of the media in covering a health crisis. Vasterman and Ruigrok (2013) reported that media coverage of epidemics or disease outbreaks tends to be sensationalist, alarming and centered on fatalities. They also noted that few messages centered on health risks or the consequences of certain health behaviors. In contrast, Collinson et al. (2015) found that media messages were effective and capable of educating people and preventing the spread of diseases. While keeping these two schools of thought in perspective, this study found that the two online sites in Ghana paid little news attention to the meningitis outbreak, in terms of both frequency and depth of coverage. The coverage was, in that regard, and in terms of the focus on fatalities, akin to the findings of Berry et al. (2007) in their study of media coverage of the SARS outbreak.

\section{Meningitis in the News}

Nearly $80 \%$ of stories analyzed were straight news stories. When evaluating health coverage this seems reasonable, as it may be difficult to create feature stories particularly during a health crisis. We also reviewed the stories for level of prominence, highlighting the perceived value of the news. Again, the prominence of meningitis stories, measured in terms of the use of story enhancements like photographs and videos show that the majority of the stories were presented as straight news, signaling the threat tenor of the stories. Furthermore, Cissel (2012) discovered a significant relationship exists between the length of a news story and its importance. News stories online are generally similar in length as the printed version with 500-800 word stories. However, reporters for online publications must master "crafting information, concise headlines, summaries, hyperlinks to longer versions of a story" (George-Palilonis 2013: 107). Particularly since this study analyzed online news articles the length of the story helped convey its importance. The story lengths recorded for this study indicated that the meningitis reports had little prominence. More than half $(51 \%)$ of the stories had less than 400 words, thus categorizing them as short articles. Given the limited word count, it would seem that the stories did not contain sufficient explanatory reports on meningitis as would provide readers with the knowledge, skills and facilitation needed to educate and help curtail the spread of the disease.

In terms of timing of the publications, the Ghana Health Service reported the particular outbreak of meningitis in December 2015. However, this study found no reports of the disease in December. Although the majority of stories were posted in January and February, the December void suggests that the media failed to perform their surveillance duty of alerting and warning the public of impending health risks. When the media abandon the surveillance role, the public are less aware of health threats and prevention measures. In March, the media outlets reported a decline in the cases of meningitis. Thus, publishing only nine articles. The decline in number of online news reports 
reflect the trend in news attention cycles, when coverage peaks and wanes with the passage of time, as Vasterman and Ruigrok (2013) found.

Lastly, we determined prominence of coverage by coding for story enhancement. Online news platforms are expected to engage users through story enhancement or visual communication elements. Websites are created to utilize multimedia (photo, video, and audio). Findings indicated that the preponderance of stories $(86 \%)$ were accompanied by pictures; although stories combining multiple elements of text, pictures, audio and video were less than $3 \%$ each. This discovery shows that the online platforms rarely exploited the advantages to story enhancement by the combination multimedia tools. Best practices suggest that online publications are expected to capitalize on the space and multimedia platforms available (George-Palilonis 2013). In fact, news stories published online are expected to combine pictures, voice and videos in order to tell stories better and increase trust and credibility among its audiences.

\section{Dominant Frames}

Similar to findings by Shih et al. (2008), the study revealed that consequence and action frames were the majority frames employed, with $50 \%$ and $32.5 \%$, respectively. Accordingly, the frames of consequence and action consistently appeared in the coverage. This supports the findings of this study that the online media tend to concentrate on fatalities, risks and consequence when reporting on disease outbreaks. This often contributes to a sense of alarm and panic about the disease (Vasterman and Ruigrok 2013). In examining frames, we considered also the tone of the story, key issues reported, subject matter of the story and frames identified in the in media coverage of meningitis. The categories of frames included consequence, uncertainty, action, conflict, reassurance and new evidence. According to Lakoff (2004), the tone of voice ultimately contributes to frames which are supported by alarming or reassuring words. Contrary to findings by Fogarty et al. (2011) that majority of stories contained elements of alarm intended to convey seriousness of the disease, the findings of this study revealed that most news articles had neutral tones and contained different perspectives from sources about the disease. Second, when we accessed the key issues reported our findings mirrored Fogarty et al. (2011) in the sense that the majority of issues reported concentrated on mortality and infection rates as the disease spread. Consequently, most news stories merely tracked and reported the increasing number of meningitis deaths and cases. Third, as we examined how these two online media framed and packaged reports, we discovered that the media reports generally highlighted issues of mortality and infections rather than modes of disease transmission, prevention and control. As a result, the media will be unable to properly educate readers, viewers and listeners about the necessary precautionary measures to reduce the spread of meningitis. 


\section{Interviewing Sources}

In order to help audiences, understand potential health threats as well as attribute credibility to the stories, journalists must select their sources wisely. We reviewed the sources of information published in the online news stories and discovered that the media relied more on health officials and government representatives, such as Ministry of Health officials, as primary sources of information during the meningitis outbreak. The majority of sources cited in news stories were officials from the Ministry of Health, the Ghana Health Service as well as doctors at health practitioners. Nonetheless, the online media did not engage real people in their stories, the voices of every day Ghanaians affected were missing from the reports. The failure to connect on a more local level hindered the websites' ability to capture human interest. Subsequently, the voices of those infected with meningitis and residents affected by the disease were missing from reports. We discovered that although sources such as Ministry of Health representatives and health professionals were considered as credible sources, these sources did not provide stories with depth and a variety of perspectives. For instance, health officials mostly provided meningitis statistics e and government actions to prevent the spread of the disease. Too often the Ghanaian journalists have taken the more accessible or easier way to report on a serious health crisis. In order to have more complete, in-depth reports journalists would have to spend more time reporting different perspectives, particularly residents who direct experiences with the disease.

\section{Conclusion}

In summary, it is well documented that media have an influential role in the public responses to health issues. The mass media - print, television, radio and online - have a wide reach to Ghanaian readers, viewers and listeners. Globally, media continue to have substantial power in setting agendas, informing the public of what they should be concerned about and what actions to take. We argue that the two online media outlets studied have much room for improvement in terms of covering the nation's health crisis. Our study set out to determine the level of prominence, frames and sources cited in online news media's coverage of a recent meningitis outbreak.

The study determined that during the outbreak, the media paid more attention to fatalities/ mortality rates and the number of new meningitis cases. We also discovered that consequence and action frames were the dominant frames in reporting on the meningitis outbreak. In terms of educating, informing or alerting the public about the disease, the research findings suggest that media coverage was relatively low until the number of deaths began to increase making that particular outbreak a national issue. Moreover, the media failed to source beyond health and government officials, neglecting to incorporate the voices of those directly affected during the health crisis. The findings also highlighted the absence of the surveillance function. The online 
media failed to play the surveillance role of alerting and warning the public of impending health risks. In fact, few stories highlighted ongoing meningitis trends or mentioned the outbreak as a national health conversation.

While the study provided some insight on how online media are covering an annual health threat to Ghanaians, there were several limitations. A major challenge centered on retrieving news articles from both online media platforms. Both platforms did not have an updated section dedicated to news archives to enable a systematic data collection process. As such the data retrieved for analysis only consisted of stories with direct reference to meningitis while it may be possible that there were other stories published on meningitis which were not made available through keyword searches. Beyond the content analysis researchers understand the value of interviewing online editors about their meningitis coverage. Semi-structured interviews would have also enhanced the data, but due to limited time those interviews did not take place.

\section{Recommendations}

Still, based on the findings of this online media study, we make the following recommendations:

- Since meningitis is a re-occurring national health threat in Ghana, the communication personnel at the Ministry of Health, Ghana Health Services and other responsible agencies should ensure that media coverage of meningitis will be more timely, alerting authorities and the public. With proper health messaging, earlier media reports have the opportunity to influence Ghanaians to take precautionary health measures.

- Journalism training on covering health, particularly disease outbreaks such as meningitis would be a great service for media outlets and the public.

- Health organizations should attempt to create multimedia press kits to model best practices for online media health reports.

Non-governmental agencies should create a guide for covering meningitis which includes, a range of sources on meningitis, including non-official sources: a village health care worker or a person who has lost a loved one as result of the disease. This content-analysis provided a mere snapshot of online media coverage in Ghana. Again, talking to media gatekeepers and agenda-setters about how they view health coverage, particularly meningitis coverage would help health communication professionals and medical personnel understand how mass media can play a greater role in curtailing the outbreak of meningitis in Ghana. Additional studies also could expand from online to print and broadcast media. Researchers report that journalists tend to send out reassuring messages and minimize risks related to the issue when reporting about those issues in their own community (Griffin et al. 1995, cited in Shih et al. 2008). A study on community media coverage verses more national efforts would also greatly add to the discussion. 


\section{Acknowledgements}

Our thanks to Ms Doreen Misrowoda, a graduate of the Master of Arts in Communication Studies program, at the University of Ghana, Legon for her collection of data and research assistance.

\section{References}

Agier L, Broutin H, Bertherat E, Djingarey HM, Lingani G, Perea W et al. (2013) Timely detection of bacterial meningitis epidemics at district level: a study in three countries of the African meningitis belt. The Royal Society of Tropical Medicine and Hygiene 107: 30-36.

Awingura AP, Awoonor-Williams JK (2015) An Evaluation of Meningitis Surveillance in Northern Ghana. International Journal of Tropical Disease 12(2): $1-10$.

Berry T, Wharf-Higgins J, Naylor P (2007) SARS wars: An examination of the quantity and construction of health information in the news media. Health Communication 21(1): 35-44.

Carducci A, Alfani S, Sassi M, Cinini A, Calamusa A (2011) Mass media health information: quantitative and qualitative analysis of daily press coverage and its relation with public perceptions. Patient Education Counseling 82: 475-478.

Cassidy WP (2007) Online news credibility: An examination of the perceptions of newspaper journalists. Journal of Computer-Mediated Communication 12: 478498.

Chen N, Murphy TS (2011) Examining the role of media coverage and trust in public health agencies in h1ni influenza prevention. International Public Health Journal $3(1): 45-52$.

Cissel M (2012) Media framing: a comparative content analysis on mainstream and alternative news coverage of occupy wall street. The Elon Journal of Undergraduate Research in Communication 3(1): 67-76.

Collinson S, Khan K, Heffernan MJ (2015) The effects of media reports on disease spread and important public health measurements. PLOS ONE 10(11): e0141423.

Cortesi S, Gasser U (2015) Youth online and news: A phenomenological view on diversity. International Journal of Communication 9(1): 1425-1448.

Entman RM (1993) Framing: Toward clarification of a fractured paradigm. Journal of Communication 43(4): 51-58.

Erickson RV, Baranek PM, Chan JB (1989) Negotiating Control: A Study of News Sources. Toronto: University of Toronto Press.

Eysenbach G (2008) Credibility of health information and digital media: new perspective and implications for youth. In MJ, Metzger, AJ Flanagin (Eds.), Digital Media, Youth, and Credibility (123-154). Cambridge: MIT Press.

Flanagin A, Metzger, M (2000) Perceptions of Internet information credibility. Journalism \& Mass Communication Quarterly 77(3): 515-540.

Fogarty A, Imison M, Chapman S, Holding S (2011) Communicating uncertainty: How Australian television reported H1N1 risk in 2009. Bio Med Central Public Health 11: 181-189.

George-Palilonis J (2013) The multimedia journalist: storytelling for today's media landscape. Oxford: Oxford University Press. 
Gitlin T (1980) The whole world is watching: Mass media in the making and unmaking of the new left. Berkeley: University of California Press.

Goffman E (1974) Frame analysis: An essay on the organization of experience. London: Harper and Row.

Goldsmith DJ, Albrecht T (2011) Social support, social networks, and health. In T Thompson, R Parrott, JF Nussbaum (Eds.), Routledge Handbook of Health Communication (2nd edn.) (335-348). New York: Routledge.

Hilton S, Hunt K (2010) UK newspapers' representations of the 2009-10 outbreak of swine flu: One health scare not over-hyped by the media? Journal of Epidemiology and Community Health 65(10): 941-946.

$\mathrm{Hu}$ Y, Sundar SS (2010) Effects of online health sources on credibility and behavioral intentions. Communication Research 37(1): 105-132.

Kim D, Johnson T (2009) A shift in media credibility: Comparing Internet and traditional news sources in South Korea. International Communication Gazette 71: 283-302.

Kiousis S (2011) Agenda-setting and attitudes: exploring the impact of media salience on perceived salience and public attitude strength of us presidential candidates from 1984 to 2004. Journalism Studies, 12(3): 359-374.

Kline K (2006) A decade of research on health content in the media: the focus on health challenges and sociocultural context and attendant informational and ideological problems. Journal of Health Communication 11(1): 43-59.

Lakoff G (2004) Don't think of an elephant. Know Your Values and Frame the Debate-The Essential Guide for Progressives. White River Iunction, VT: Chelsea Green.

McCombs M (2005) A look at agenda-setting: Past, present and future. Journalism Studies 6(4): 543-557.

Medeiros DFN, Massarani L (2010) Pandemic on the air: A case study on the coverage of new influenza A/H1N1 by Brazilian prime time TV news. Journal of Science Communication 9(3).

Messner M, Distaso MW (2008) The source cycle. Journalism Studies 9(3): 447-463.

Perrin A (2015) Social networking usage: 2005-2015. Pew Research Center. October 2015. Retrieved from goo.gl/EoYfeH.

Peters E (2011) Affect and emotion. In B Fishhoff, NT Brewer, JS Downs (Eds.), Communicating risks and benefits: An evidence-based user's guide. Silver Spring, MD: FDA, US Department of Health and Home Services.

Pribble MJ, Fowler FE, Kamat VS, Wilkerson MW, Goldstein MK, Kargarten WS (2010) Communicating emerging infectious disease outbreaks to the public through local television news: Public health officials as potential spokespeople. Disaster Medicine and Public Health Preparedness 4(3): 220-225.

Scheufele DA (1999) Framing as a theory of media effects. Journal of Communication 49(1): 103-122.

Schiavo R (2014) Health communication: From theory to practice. San Francisco, CA: Jossey-Bass.

Shih T, Wijaya R, Brossard D (2008) Media coverage of public health epidemics: linking framing and issue attention cycle toward an integrated theory of print news coverage of epidemics. Mass Communication and Society 11(2): 141-160.

Steinbrook R (2000) Medical journals and medical reporting. The New England Journal of Medicine 342: 1668-1671.

Tchuenche ND, Bhunu CP, Smith RC, Bauch CT (2011) The impact of media coverage on the transmission dynamics of human influenza. BMC Public Health 11. 
Tietaah G (2015) Abusive language, media malaise and political efficacy in Ghana. In K Ansu-Kyeremeh, A Gadzekpo, M Amoakohene (Eds.), A Critical Appraisal of Communication Theory and Practice in Ghana. University of Ghana Reader Series. Accra: Digibooks.

Vasterman P, Ruigrok N (2013) Pandemic Alarm in the Dutch Media: Media Coverage of the 2009 Influenza (H1N1) Pandemic and the role of Expert Source. European Journal of Communication. 28(4): 436-453.

World Health Organization (2017) Epidemic meningitis control in countries of the African meningitis belt. World Health Organization's Weekly Epidemiological Record 13: 145-164. 
